\title{
THE EPISTEMIC ROLE OF DESIGN EDUCATION IN AN ENGINEERING SCIENCE DEPARTMENT
}

\author{
Rubaina Khan, Lisa Romkey, Nikita Dawe and James D. Slotta \\ University of Toronto \\ rubaina.khan@mail.utoronto.ca
}

\begin{abstract}
Design courses in engineering education provide the space in the curriculum to synthesize theoretical and technical knowledge gained from coursework. As students gain new knowledge and acquire skillsets, there is a need to demonstrate how the learning connects to their professional actions. With practice and rehearsals, students realize the values and dispositions they need to possess to be deemed a disciplinary member. In this paper, through semi-structured interviews of six design instructors, we report what instructors think is the epistemic role of design courses in instilling disciplinary values in an Engineering Science program.
\end{abstract}

Keywords: discipline-based education research, design spines, design education, curriculum coherence

\section{INTRODUCTION}

At the core of Discipline-Based Education Research (DBER) is the recognition that educational research approaches are not a "one size fits all" effort. Understanding how learning in the discipline occurs is required to improve students' learning process and experience [1]. Hence, it is important to understand how engineering design courses contribute to the development of our students' professional identities.

Design education allows students to experience and value the flexibility and solution-focused nature of engineering work within multidisciplinary contexts. However, the struggle from a curriculum perspective is to balance engineering knowledge and design experiences that would support a holistic engineering education [2]. Design has been explicitly highlighted as a skill and experience that undergraduate engineers need to achieve. Mawson [3] argues that design taught in sequences portrays that the design process is a linear experience; this is misleading, oversimplified, and often does not represent the ill-defined or wicked problems that the twenty-firstcentury design engineer will face at work [4]. More design courses today are characterized by evolving patterns of practice that transcend disciplinary and conceptual boundaries. Also, engineering students should see the connections amongst the design sequences and their experiences while being exposed to different perspectives on the field [5].

Students experience different ways of knowing and working due to the exposure of cross-faculty appointments who teach in other departments and conform to their discipline standards. However, it can be argued that along with exposure to different ways of thinking and working, students need to learn to value, manage, and synthesize different cross-disciplinary approaches and choose the right approach or tool for the problem at hand through value modeling techniques [6]. Design education enables students to explore and act upon issues plaguing the world and address them through creativity by seeking unique, unusual, unconventional, and unexpected solutions [7].

This research study was conducted to uncover the role design courses play in developing the professional identity of graduates as perceived by design instructors in the Division of Engineering Science at the University of Toronto. The ability to recognize and practice the goals, rules, and strategies of discipline is known as epistemic fluency [8]. Using a conceptual framework that looks into epistemic fluency of professional work, the qualitative data from semi-structured interviews of design instructors were analyzed to understand what they thought was the purpose of teaching students design. The results show the nuances that design courses serve in instilling disciplinary values and emulating future work scenarios.

\section{LITERATURE REVIEW}

\subsection{Purpose of design education}

Undergraduate engineering students need authentic learning experiences that replicate real-world scenarios in their profession. Most engineering curricula have dedicated courses towards advanced math and science, and therefore explicit design experiences are required for synthesis and application of theoretical knowledge. Apart from serving as epistemic practices of the engineering profession, design courses emulate the social aspects of the profession, such as teamwork [9], resource management [10], and communication with stakeholders [11]. Reform in undergraduate engineering curriculum, such as instilling 
21 st-century competencies in students, are often implemented in the design courses [12].

A typical structure involves general design courses in the first year and ending with a disciplinary capstone design course in the final year. The design courses at the undergraduate level aim to demonstrate how fundamental engineering science connects to developing conceptual ideas, introduce tools for process, and scrutinize the various elements that go into design, such as cost and client preference.

Students are exposed to ways of knowing in their discipline through their interactions with curriculum expectations and interactions with experts in the fields their instructors [13]. Design courses also serve as a space where tools and concepts learned in other engineering courses may find purpose and relevance to real-world problems [14]. Students develop disciplinary dispositions as they proceed in their undergraduate journey, eventually forming their professional identity. Expectations of students' knowledge and skills are mandated by accreditation boards [15], influenced by industry needs [16], and aspired by alumni's career journeys [17].

\subsection{Design Pedagogy and Philosophy}

Faculty members who teach design courses are often not trained to develop a pedagogy for design learning and may lack experience working in or understanding other disciplines [20]. Professors who are domain experts may adhere to instructional techniques familiar to their field and may present concepts isolated from other disciplines [18]. Apart from pedagogical and content aspects of design courses, teaching members need to be comfortable with unpredictable and chaotic behaviors and situations in the classroom [19].

A design philosophy is perpetuated in a course by using a specific dialect, discourse, and the judgments or consensus made by the instructor [20]. Undergraduate engineering students, through their design course, learn how to operate within a context, influence their audience and develop an intuition to balance their position and the needs of the users [21]. Designs are commonly conveyed through representations, and Galle postulates that the role of these representations is closely tied with the design philosophy practiced [22].

Faculty members teaching design come into the design classroom or studio with their design philosophy. Students may notice the nuances in their instructors' philosophies when different design elements are emphasized in each course. The design models employed by the faculty to show how the design is and can be done are a representation of their philosophies [18]. Furthermore, faculty's philosophies of design may influence the design goals and the variety of design problems addressed in the course, such as - routine designs, redesigns, and nonroutine designs. Students can be exposed to different philosophies through their professors and may lean towards a particular school of thought when they graduate.

\subsection{Design Spines}

Design experiences have been implemented in engineering schools typically as a cornerstone and a capstone design course. Recently, institutes have reasons to believe that design experiences need to be more prevalent and linked across the curriculum [23][24][25]. As such, a design spine is a type of learning progression to teach design that progresses by raising stakes, such as first designing for issues with known solutions and progressing towards addressing real-world and research challenges [26]. The author in [24] also points out that a design spine, through several design cycles, may help students overcome habits detrimental to design, such as jumping to propose solutions.

A design spine may also be connected through employing a design methodology where some aspects of the framework are emphasized in each course to develop confidence and competence through repetition [26], which is difficult to achieve in a bookend (cornerstone and capstone) curriculum approach [28]. A design spine/learning progression provides a structure that can persist through changes such as scaling up a program, increased offerings of courses, and changing of instructors. The design spine provides space for students to actively participate in and reflect upon the profession's expectations, which eventually allows them to develop their identities as engineers [29].

\subsection{Coherence in Program}

As with any sequence of courses and experiences, students should feel the various parts of the program are interconnected and purposeful. Engineering programs are often plagued by fragmentation within program coursework and between theory and practice. Students must experience coherence in their program if they are to overcome difficulties in integrating theory and practice [30], experience their program as a whole instead of as "disconnected continents" [31], and find their professional identity [32]. Often, there is a disconnect between planned and enacted curriculum [33]. Students need aligned experiences to build upon their existing knowledge base and integrate new knowledge and interpretations. In addition, coherence in a program is enhanced when educators start to think collectively about what their graduates need instead of focusing on their personal wishes [34].

\section{Methodology}

\subsection{Conceptual Framework: Epistemic Fluency}

Every academic discipline characterizes problems differently, and their solutions typically require distinctive 
kinds of knowledge [8]. The authors in [35] call these characteristic patterns of actions for effective inquiry as "epistemic games". Engineering Science, as the context of this research study, is a discipline [36] that was been established to integrate science and engineering and speak to the gaps posed by just highlighting the practical work of engineers.

Design courses in the engineering curriculum help novice community members identify and practice their discipline's epistemic games. Through instruction, emphasis on specific topics, and weightings on assessments, instructors show students the types of knowledge and dispositions valued in the profession. The capability to recognize these patterns of knowledge and action is known as epistemic fluency [8].

Fluency in one's profession requires students to have a deep understanding of the nature and demands of their profession. This expectation then falls upon educators to know how to design and manage a learning environment that offers reliable forms of assessment that support the profession's demands. Therefore, epistemic fluency also allows a graduate to know the strengths they bring in with their professional knowledge and recognize that limitations can be overcome by collaborating with professionals with different kinds of knowledge. Therefore, professional education needs to influence, and be influenced by, a deep appreciation and understanding of how various professionals intertwine diverse ways of knowing - in a nutshell, understanding of epistemic fluency [37]

The conceptual framework used to analyze the qualitative data from semi-structured interviews guided the coding of the interview transcripts. The framework consists of four categories that conceptualize the epistemic knowledge required for professional practice: -

1. Reflective Rational - the types of knowledge and experiences related to the linking of theoretical understanding with practice.

2. Reflective Embodied is the act of taking on a professional 'skin' using fine-tuned professional skills and identity.

3. Knowledge Building - these are ways to challenge students' ideas that are future-oriented and understanding the dynamic nature of their profession

4. Relational Expertise - the awareness and practices required to engage at the intersections between various professional fields and different ways of knowing.

\subsection{Research Context}

The Division of Engineering Science at the University of Toronto offers a multidisciplinary undergraduate program. Engineering Science is a discipline that was established in the 1930s to integrate science and engineering and address gaps that resulted through over emphasis on the practical aspects when training engineers.
Engineering Science was initially "Engineering Physics" but later it was changed to "Engineering Science" when chemical engineering was offered as a major. Currently, the "Science" in Engineering Science signifies the program's rigorous and general foundation in science and mathematics. Students in this program are admitted in as cohorts who go through two years of foundation courses followed by the two years specialising in the option they choose as their major.

This study is part of a multi-year project titled ROLE (Realigning Outcomes with Learning Experiences), designed to realign the curriculum, pedagogy, and brand with the goals of the Division of Engineering Science. More specifically, the project includes four main components: (i) the review and refinement of program goals; (ii) the redesign of several aspects of the program learning environment; (iii) finding new ways to support our students and faculty; and (iv) examining our brand strategy and admissions criteria. The first step in the project is to understand the state of Engineering Science as an academic discipline and to understand better its role in the broader engineering and science landscape [36].

\subsection{Data Collection and Analysis}

As part of the more extensive program evaluation study described above, six instructors who teach design in the Engineering Science program shared their perspectives on the role of design for the program through semi-structured interviews. Interviewees were asked to elaborate on how the program was distinct from other engineering programs and how this influenced their design pedagogy. The aim of this study to is find ways to strengthen the design spine of the Engineering Spine program that supported students in building their professional identity.

A microanalytic multiple case study approach was adopted to provide detailed understandings of the epistemic role of design in the program [38]. Data collected from the instructors were analyzed using an inductive process [39] and coded to identify prominent themes through the emergence of "patterns and processes, commonalities and differences" [40]. To reduce researcher bias, thematic coding and display charts were used [38]. To address Lincoln and Guba's four general types of trustworthiness in qualitative research (credibility, transferability, dependability, and confirmability), stakeholder checks and checks of interrater reliability were conducted [41].

\section{FINDINGS}

The findings are categorized according to the conceptual framework that guided the coding process.

\subsection{Reflective Rational}

Ease with practical knowledge and skills - Engineering Science students come into their design courses with strong 
mathematical and scientific knowledge. Therefore, design instructors aim for their courses to be a space for students to apply their deep theoretical understandings in solving messy and ill-structured challenges. The design space often challenges students to get out of their comfort zone, building solutions, or figuring out the constraints that would implicate a design's objectives. These findings may be expected in other engineering departments; however, design instructors in this department emphasized that Engineering Science students lack the ease an engineer should have with technical apparatus and practical aspects of their professional world.

A first-principles approach to design - The foundation years of the curriculum emphasize taking a first-principles approach to learning. At the end of the foundation years, students are eloquent at creating mathematical models and can unpack complex scientific concepts to their underlying phenomenon. With the same intentions, the design courses aim to provide the space to explore the nature of design and how it connects to the engineering profession. The foundation design courses provide a considerable amount of time unpacking one's positionality as it connects with their profession and how their profession as engineers impact society.

\subsection{Reflective Embodied}

Explicit connections to the professional world Engineering science students pursue a broad spectrum of careers - ranging from academic research to work in the public sector. From alumni surveys, it is a common trait that Engineering Science students change industries several times within their careers. Hence, instructors believe that design principles and experiences are essential for students to be prepared for various situations that they may face in their careers. In addition, instructors design problem statements that purposefully aim to showcase that design decisions play an essential role in innovation. Lastly, instructors wanted their students to experience that the decision-making process in their profession is entangled with the legislature, professional codes, and the society at large.

Scaffolds for identity formation - Design instructors believed that the design courses heavily shaped students' identity. They attributed their beliefs to the openness of design courses that offers students the space to question the intersectionality of their background, purpose, professional responsibilities, and membership in society. Through selfassessments, students define their aspirations and roles they hope to fulfill as Engineering Science graduates. These reflective acts also contribute to their metacognitive development as they connect their learning to their identity. In addition, instructors pointed out that reflective exercises have to be strewn across the program to allow students to be in a continuous process of meaning-making of their learning and how it contributes to their professional identity.

CEEA-ACEG21; Paper 193

University of Prince Edward Island; June $21-23,2021-4$ of 7 -

\subsection{Knowledge Building}

A balance between science and engineering - Several design instructors, thought that the role of engineering science graduates was to advance scientific knowledge that has relevance to solving societal challenges. To strike a balance between scientific inquiry and engineering decision-making, instructors believe that design courses help students explore their discipline's nature in its entirety. The process, at times, is challenging because design principles appear intuitive but challenging to put into practice. In addition, Engineering Science students are comfortable with scientific and mathematical challenges and often struggle with the messiness and diversity of approaches to designing solutions.

Building cognitive structures for inquiry - As discussed earlier, to be prepared for the broad career opportunities Engineering Science graduates pursue, students need to know how their skills and knowledge can be transferred in different scenarios. Design instructors identified the need to develop cognitive capacities to unpack unknown technology, scientific concepts, and processes by experiencing unfamiliar situations in their design courses. The chance to experience uncertain situations allows students to be confident in the face of new challenges and opportunities in the future that do not have clear answers.

\subsection{Relational Expertise}

Grooming the next-generation entrepreneurs - The department of Engineering Science, historically, produced researchers and instructors who worked in academia. Over the last few decades, graduates have been increasingly involved in various entrepreneurial work. Instructors have responded to this career trajectory by showcasing the various ways to approach design. In addition, students are expected to be rigorous in justifying their design decisions and communicating them to potential funders. Lastly, with relatively small cohort sizes, instructors can spend considerable time in dialogue with students about engineering design dilemmas and the available technology to support innovation.

Awareness of other design philosophies - Some design instructors pointed out design itself has its distinct ways of knowing, unique core ideas, and several pathways one can go about to tackle design problems. The design courses in the Engineering Science design spine are taught by instructors who hold different design philosophies. The instructors anticipated that exposure to varied design philosophies would allow students to see the many ways to frame the same problem. This experience prepares graduates to be equipped for the range of industry and academic jobs they typically pursue. 


\section{DISCUSSION}

\subsection{Epistemic Role of the Instructor}

The findings in this study show that the foundational design courses for students is instrumental in developing an disciplinary identity as well as developing critical consciousness. An interesting purpose of the foundational design courses in the department of Engineering Science is that it focuses on the individual students' positionality as a future engineer in society. Through introspection, students address the biases they bring in to their teams' decisions as they develop, validate, and verify complex engineering systems. Engineering design courses are often structured around making key decisions that require both deep thinking and efficiency. However, biases may come into play when the focus in on quick turnaround decisionmaking [42]. In addition to making decisions for engineering work to progress, reflective exercises are of paramount importance when teaching engineering students to understand that the intersectionality of relevance of context, human-centeredness, and contribution to community should be part of their daily practice of engineering. These exercises may often be constricted in engineering education as they can be contextualized in artificial situations and the power dynamics between students and educators is present [43].

It can be argued that learning is not simply a cognitive occurrence, but the students' ability to effectively participate in discourses within their discipline's community using their advanced knowledge. Engle and Conant [44] suggests that productive disciplinary engagement can be fostered by designing learning environments that support (a) problematizing subject matter, (b) giving students authority to address such problems, (c) holding students accountable to others and to shared disciplinary norms, and (d) providing students with relevant resources. Therefore, more investigation is required to understand how Engineering Science students question and re-evaluate accepted truths and whether this practice continues as they move into their last two years of specialisation.

\subsection{Teaching in Interdisciplinary Contexts}

Engineering Science students experience design related to their specialization after their foundation years. Instructors whose home department is different from Engineering Science teach these students who are moving between disciplines. Therefore, instructors teaching in the specialization years need to create courses with disciplinary epistemic aims while students are still developing professional identities related to engineering science. It does not mean that professional identities only occur just through coursework, but the collective professional identity formation can be scaffolded through curricular interventions. Hence, internal influences on curricula, such as instructors' perceptions, are important to understand and communicate within the program [45] These perceptions bring forward instructor's disciplinary views and design philosophy, which influences how they perceive how students would gain epistemic fluency in the discipline. The design spine of the Engineering Science department can be strengthened by setting its vision that must be clearly articulated by leadership to instructors. The vision can help guide conversation among the multidisciplinary design instructors to take on interdisciplinary approaches that would promote students' abilities to integrate and synthesize concepts and knowledge as they experience different disciplines [46]. Finally, Engineering Science graduates often experience several career changes while they practice their profession. Therefore, reflecting on the process of developing a professional self is essential to recognize through iterations of adapting to new knowledge [47].

\section{CONCLUSION}

This research was conducted as part of a program evaluation of an Engineering Science program to align learning outcomes of the curriculum with the profession's expectations. Six design instructors were interviewed, and findings showed that design education plays a pivotal role in shaping students' professional identity and provides authentic disciplinary learning. The next steps will be in engaging and understanding students' perceptions of the design spine and in what ways do they understand the expectations of their profession.

\section{Acknowledgments}

We would like to acknowledge the Office of the Dean in the Faculty of Applied Science and Engineering, University of Toronto, for their generous support of our research.

\section{References}

[1] M. Borrego and J. Bernhard, "The Emergence of Engineering Education Research as an Internationally Connected Field of Inquiry," J. Eng. Educ., vol. 100, no. 1, pp. 14-47, 2011, doi: https://doi.org/10.1002/j.21689830.2011.tb00003.x.

[2] C. L. Dym, A. M. Agogino, O. Eris, D. D. Frey, and L. J. Leifer, "Engineering Design Thinking, Teaching, and Learning," J. Eng. Educ., vol. 94, no. 1, pp. 103-120, 2005, doi: https://doi.org/10.1002/j.2168 9830.2005.tb00832.x.

[3] B. Mawson, "Breaking the shackles: Beyond the design process," Auckl. N. Z. Cent. Technol. Educ., 2003.

[4] N. Cross, Designerly Ways of Knowing. London: SpringerVerlag, 2006. doi: 10.1007/1-84628-301-9. 
[5] L. Bækgaard and C. Lystbaek, "Learning to do knowledge work: A framework for teaching research design in engineering education," Int. J. Eng. Educ., vol. 35, pp. 333-344, Jan. 2018.

[6] A. Bertoni, "Introducing value driven design in engineering education: teaching the use of value models in preliminary design," Int. J. Technol. Des. Educ., vol. 30, no. 3, pp. 531-552, Jul. 2020, doi: 10.1007/s10798-01909511-x.

[7] D. Cropley and A. Cropley, Fostering Creativity: A Diagnostic Approach for Higher Education and Organisations. 2009.

[8] D. Morrison and A. Collins, "Epistemic Fluency and Constructivist Learning Environments," Educ. Technol., vol. 35, no. 5, pp. 39-45, 1995.

[9] M. T. Oladiran, J. Uziak, M. Eisenberg, and C. Scheffer, "Global engineering teams - a programme promoting teamwork in engineering design and manufacturing," Eur. J. Eng. Educ., vol. 36, no. 2, pp. 173-186, 2011, doi: 10.1080/03043797.2011.573534.

[10] G. Pahl, K. Wallace, L. T. M. Blessing, W. Beitz, and F. Bauert, Engineering Design: A Systematic Approach, Third Edition. London: Springer London, Limited, Springer London, Springer, 2013. doi: 10.1007/978-184628-319-2.

[11] M. Deininger, S. R. Daly, J. C. Lee, C. M. Seifert, and K. H. Sienko, "Prototyping for context: exploring stakeholder feedback based on prototype type, stakeholder group and question type," Res. Eng. Des., vol. 30, no. 4, pp. 453-471, 2019, doi: 10.1007/s00163-019-00317-5.

[12] Educating Engineers: Preparing 21st Century Leaders in the Context of New Modes of Learning: Summary of a Forum. National Academies Press.

[13] J. Heywood, Empowering professional teaching in engineering: sustaining the scholarship of teaching, 1st ed. Morgan \& Claypool Publishers, 2018.

[14] Jesús Zamora-Bonilla and Ian Jarvie, "Idealised Representations, Inferential Devices and CrossDisciplinary Tools: Theoretical Models in Social Sciences." SAGE Publications Ltd, London, 2011. doi: 10.4135/9781473913868.n29.

[15] D. Schaefer, G. Coates, and C. Eckert, Eds., Design Education Today: Technical Contexts, Programs and Best Practices. Cham: Springer International Publishing, 2019. doi: 10.1007/978-3-030-17134-6.

[16] M. V. Jamieson and J. M. Shaw, "Teaching engineering innovation, design, and leadership through a community of practice," Educ. Chem. Eng., vol. 31, pp. 54-61, 2020, doi: $10.1016 /$ j.ece.2020.04.001.

[17] G. Saunders-Smits and E. de Graaff, "Assessment of curriculum quality through alumni research," Eur. J. Eng. Educ., vol. 37, no. 2, pp. 133-142, 2012, doi: 10.1080/03043797.2012.665847.

[18] M. A. Peters, "Education and 'societies of control' from disciplinary pedagogy to perpetual training," Contemp. Read. Law Soc. Justice, vol. 3, no. 1, pp. 7-, 2011.

[19] K. Budge, C. Beale, and E. Lynas, "A Chaotic Intervention: Creativity and Peer Learning in Design Education," Int. J. Art Des. Educ., vol. 32, no. 2, pp. 146156, 2013, doi: 10.1111/j.1476-8070. 2013.01734.x.

[20] N. F. O. Evbuomwan, S. Sivaloganathan, and A. Jebb, “A Survey of Design Philosophies, Models, Methods and
Systems," Proc. Inst. Mech. Eng. Part B J. Eng. Manuf., vol. 210, no. 4, pp. 301-320, Aug. 1996, doi: 10.1243/PIME_PROC_1996_210_123_02.

[21] M. Kreimeyer and U. Lindemann, Complexity Metrics in Engineering Design: Managing the Structure of Design Processes. Springer Science \& Business Media, 2011.

[22] P. Galle, "Design as intentional action: a conceptual analysis," Des. Stud., vol. 20, no. 1, pp. 57-81, Jan. 1999, doi: 10.1016/S0142-694X(98)00021-0.

[23] I. C. De los Rios and F. J. S. Charnley, "Skills and capabilities for a sustainable and circular economy: The changing role of design," J. Clean. Prod., vol. 160, pp. 109-122, Sep. 2017, doi: 10.1016/j.jclepro.2016.10.130.

[24] G. Heitmann, "Project-oriented Study and Projectorganized Curricula: A Brief Review of Intentions and Solutions," Eur. J. Eng. Educ., vol. 21, no. 2, pp. 121-131, Jun. 1996, doi: 10.1080/03043799608923395.

[25] M. J. Pavelich, B. M. Olds, and R. L. Miller, "Real-world problem solving in freshman-sophomore engineering," New Dir. Teach. Learn., vol. 1995, no. 61, pp. 45-54, 1995, doi: https://doi.org/10.1002/tl.37219956108.

[26] E. C. Y. Chung, "The Design Spine: The Core Design Modules Behind Taylor's School of Engineering ProjectBased Learning," in Engineering Grand Challenges in Scholar Programs, G. Amouzad Mahdiraji, E. C. Y. Chung, S. N. Namasivayam, and M. Hosseini Fouladi, Eds. Singapore: Springer, 2019, pp. 17-31. doi: 10.1007/978-981-13-3579-2 2.

[27] B. Frank, D. Strong, R. Sellens, and L. Clapham, "Progress with the professional spine: A four-year engineering design and practice sequence," Australas. J. Eng. Educ., vol. 19, no. 1, 2013, doi: 10.7158/D12-016.2013.19.1.

[28] D. Kotys-Schwartz, "First-Year and Capstone Design Projects: Is the Bookend Curriculum Approach Effective for Skill Gain?," ASEE Annual Conference, J2010.

[29] S. D. Sheppard, K. Macatangay, A. Colby, and W. M. Sullivan, Educating Engineers: Designing for the Future of the Field. Book Highlights. Carnegie Foundation for the Advancement of Teaching, 2008. Accessed: Mar. 09, 2021. [Online]. Available: https://eric.ed.gov/?id=ED504076

[30] T. L. Weston and S. C. Henderson, "Coherent Experiences: The New Missing Paradigm in Teacher Education," Educ. Forum, vol. 79, no. 3, pp. 321-335, Jul. 2015, doi: 10.1080/00131725.2015.1037514.

[31] R. B. Bain and E. B. Moje, "Mapping the Teacher Education Terrain for Novices," Phi Delta Kappan, vol. 93, no. 5, pp. 62-65, Feb. 2012, doi: $10.1177 / 003172171209300514$.

[32] G. Rogers, "Learning-to-learn and learning-to-teach: the impact of disciplinary subject study on student-teachers' professional identity," J. Curric. Stud., vol. 43, no. 2, pp. 249-268, Apr. 2011, doi: $10.1080 / 00220272.2010 .521262$.

[33] K. E. Matthews and L. D. Mercer-Mapstone, "Toward curriculum convergence for graduate learning outcomes: academic intentions and student experiences," Stud. High. Educ. Dorchester--Thames, vol. 43, no. 4, pp. 644-659, 2018, doi: 10.1080/03075079.2016.1190704.

[34] P. Gagné, L. Dumont, S. Brunet, and G. Boucher, "2. Curriculum Alignment: Establishing Coherence," Collect. 
Essays Learn. Teach., vol. 6, pp. 7-12, Jun. 2013, doi: 10.22329/celt.v6i0.3763

[35] D. N. Perkins, "Epistemic games," Int. J. Educ. Res., vol. 27, no. 1, pp. 49-61, Jan. 1997, doi: 10.1016/S08830355(97)88443-1.

[36] L. Romkey, N. Dawe, and R. Khan, "What is engineering science? Defining a discipline through a cross-institutional comparison and a multi-institutional workshop," Proc. Can. Eng. Educ. Assoc. CEEA, Jun. 2020, doi: 10.24908/pceea.vi0.14168.

[37] L. Markauskaite and P. Goodyear, "Professional Work in Contemporary Contexts," in Epistemic Fluency and Professional Education: Innovation, Knowledgeable Action and Actionable Knowledge, L. Markauskaite and P. Goodyear, Eds. Dordrecht: Springer Netherlands, 2017, pp. 19-45. doi: 10.1007/978-94-007-4369-4 2.

[38] T. Hollweck, "Robert K. Yin. (2014). Case Study Research Design and Methods (5th ed.). Thousand Oaks, CA: Sage. 282 pages.," Can. J. Program Eval., Mar. 2016, doi: 10.3138/cjpe.30.1.108.

[39] D. R. Thomas, "A General Inductive Approach for Analyzing Qualitative Evaluation Data," Am. J. Eval., vol. 27, no. 2, pp. 237-246, Jun. 2006, doi: $10.1177 / 1098214005283748$.

[40] M. B. Miles and A. M. Huberman, Qualitative Data Analysis: An Expanded Sourcebook. SAGE, 1994.

[41] E. G. Guba and Y. S. Lincoln, "Epistemological and methodological bases of naturalistic inquiry," ECTJ, vol. 30, no. 4, pp. 233-252, Dec. 1982, doi: $10.1007 / \mathrm{BF} 02765185$.
[42] C. A. Toh, A. A. Strohmetz, and S. R. Miller, "The Effects of Gender and Idea Goodness on Ownership Bias in Engineering Design Education," J. Mech. Des. 1990, vol. 138, no. 10, 2016, doi: 10.1115/1.4034107.

[43] H. Trbusic, "Engineering in the Community: Critical Consciousness and Engineering Education," Interdiscip. Descr. Complex Syst., vol. 12, no. 2, pp. 108-118, 2014, doi: 10.7906/indecs.12.2.1.

[44] R. A. Engle and F. R. Conant, "Guiding Principles for Fostering Productive Disciplinary Engagement: Explaining an Emergent Argument in a Community of Learners Classroom," Cogn. Instr., vol. 20, no. 4, pp. 399483, 2002

[45] D. B. Knight et al., "Understanding Interdisciplinarity: Curricular and Organizational Features of Undergraduate Interdisciplinary Programs," Innov. High. Educ., vol. 38, no. 2, pp. 143-158, 2013, doi: 10.1007/s10755-012-92321.

[46] J. T. Klein, Creating interdisciplinary campus cultures: a model for strength and sustainability. San Francisco: Jossey-Bass, 2010.

[47] L. Scanlon, "Becoming" a Professional an Interdisciplinary Analysis of Professional Learning, 1st ed. 2011. Dordrecht: Springer Netherlands, 2011. doi: 10.1007/978-94-007-1378-9. 